\section{A genomic network to monitor Earth}

We propose that a network of genomic observatories should be established to take the planet's 'biological pulse. We invite participants to assist in the shaping of this network (see genomicobservatories.org).

DNA sequences are becoming core components of Earthmonitoring systems, and data output is soaring from genomics and other observing technologies. But sequence data alone are of limited value without the context of time and location.

Genomic observatories would integrate genomic information with environmental, socioecological and other biological data. Sequencing model ecosystems would accelerate ecological understanding.

Despite reduced sequencing costs, genomic studies are still expensive to analyse and interpret, and the expense of field collection of DNA samples remains incompressible. Genomic observatories would consolidate these efforts.

These observatories must be supported by field stations, marine labs, museums, standards organizations, research networks and sequencing centres. They should be established at existing scientifically important sites. Neil Davies Gump South Pacific Research Station, University of California Berkeley, Moorea, French Polynesia.

Dawn Field Centre for Ecology and Hydrology, Wallingford; and University of Oxford, UK. dfield@ceh.ac.uk

The Genomic Observatories Network (see go.nature.com/ rcusv3 for a list of co-authors).

\section{Reduce urban flood vulnerability}

Increasing numbers of people live in flood-prone areas worldwide. With continued development, flooding will become more frequent. Acceleration of the hydrological cycle and sea-level rise resulting from climate change could worsen the problem. We must therefore address the social, economic and political factors that force or allow some people to inhabit high-risk areas.

For example, monsoon flooding last year of Thailand's Chao Phraya River caused damage to Bangkok and surrounding areas estimated at US $\$ 45$ billion. A failure to prepare for this recurrent hazard, which has occurred in each of the past four decades, is partly to blame.

Short-term engineering approaches are not enough. Building higher dykes or cascades of dual-purpose dams may maximize water storage and reduce flood risk, but they can make people complacent and thus more vulnerable to floods.

Long-term development solutions are needed. Vulnerable cities need to be redesigned, for example by supplying transport links to metropolitan areas on higher ground.

Alan D. Ziegler ${ }^{\star}$ National University of Singapore, Singapore.adz@nus.edu.sg ${ }^{*}$ On behalf of 4 co-authors (see go.nature.com/vhe7ur).

\section{India should exploit renewable energy}

Japan's Fukushima disaster has spurred public protest in India against government plans to build new nuclear power plants, despite the Atomic Energy Commission's reassurances. We should instead be considering solar energy - a safe and sustainable option.

India receives 5,000 trillion kilowatt-hours of solar energy equivalent every year, more than the total energy the country consumes (see go.nature.com/ g89snn). India could also easily exploit wind energy to meet its power needs. Yet only a fraction of this potential is being used.

Nuclear power plants are in decline worldwide. India should follow the lead of countries such as Germany and abandon the nuclear option.

A tsunami in 2004 flooded the Kalpakkam Atomic Reprocessing Plant in Chennai. It was promptly shut down, preventing a disaster. But what if there is another tsunami? Until we abandon nuclear power, that question will continue to haunt India's policy-makers, politicians and scientists.

Govindasamy Agoramoorthy Gujarat Institute of Desert Ecology, Bhuj, Gujarat, India. agoram@mail.tajen.edu.tw

\section{Latest MMR 'dispute' is a straw man}

Journalists have for years manufactured baseless controversy over the measles, mumps and rubella (MMR) vaccine. The latest example is Eugenie Samuel Reich's report 'Fresh dispute about MMR 'fraud" (Nature 479, 157-158; 2011). Truly a classic of the genre.

You rely on one David Lewis, a retired environmental microbiologist who claims to refute findings of research fraud against Andrew Wakefield contained in my report in the British Medical Journal $(B M J)$ last January and in an accompanying editorial. You say that Lewis analysed a pathologist's bowel-histology grading sheets: these were supplied to him by Wakefield, a now struck-off former surgeon. These data underlay the claims in Wakefield's 1998 study of a "new inflammatory bowel disease" associated with MMR, based on alleged "histological diagnoses" of "non-specific colitis" (Lancet 351, 637-641, 1998; retracted, 2010).

Your report fails to identify where the $B M J$ 's conclusions (that Wakefield's work was "an elaborate fraud" (F. Godlee et al. Br. Med. J. 342, c7452; 2011)) were reliant on bowel histopathology. I invoked patient selection, clinical histories and reporting with regard to autism. These were different aspects of the study, and therefore your suggestion that somebody's opinion on the histology might "complicate" the debate about Wakefield's 'integrity' is an obvious straw-man fallacy.

You also wrongly claim that Lewis had a letter in the $B M J$ "arguing that Wakefield did not commit research fraud”. A letter was published, behind a report by me, in which I quoted five gastroenterological specialists who noted that the grading sheets indicate essentially healthy findings, where Wakefield reported disease (B. Deer $B r$. Med. J. 343, d6823; 2011). In his $B M J$ letter, Lewis then merely remarks: "I do not believe that Dr Wakefield intentionally misinterpreted the grading sheets as evidence of 'non-specific colitis."

As no such proposition was advanced (histopathology was almost the only area where, until recently, we lacked critical raw data), why did you publish an article founded upon its denial? The denier, moreover, has no qualifications in medicine or pathology; misread the grading sheets, according to their author (see go.nature.com/b9e5gu); and began working with Wakefield at a meeting of vaccine-campaign activists in Montego Bay, Jamaica, which he attended at the organizers' expense.

To breathe life into your shameless straw man, you claim that "no institution has yet ruled on the matter". You note ethics findings of a statutory tribunal of the UK General Medical Council last year, but fail to report that it found Wakefield guilty, against a criminal standard, of four counts of dishonesty over the research. These included his dishonest publication of "a misleading description of the patient population" which was "fundamental to the understanding of the study and the terms under which it was conducted" (see go.nature.com/ hg9dvs).

Brian Deer London, UK. http://briandeer.com 